\title{
PHOTOGRAMMETRIC UNDERWATER AND UAS SURVEYS OF ARCHAEOLOGICAL SITES: THE CASE STUDY OF THE ROMAN SHIPWRECK OF TORRE SANTA SABINA
}

\author{
A. Calantropio ${ }^{1}$, F. Chiabrando ${ }^{1, *}$, R. Auriemma ${ }^{2}$ \\ ${ }^{1}$ Laboratory of Geomatics for Cultural Heritage (LabG4CH), Department of Architecture and Design (DAD), Polytechnic \\ University of Turin, Viale Pier Andrea Mattioli, 39, Torino (TO), Italy - (alessio.calantropio, filiberto.chiabrando)@ polito.it \\ ${ }^{2}$ Department of Cultural Heritage, Università del Salento, Via Dalmazzo Birago, 64, Lecce (LE), Italy - rita.auriemma@unisalento.it
}

\author{
Commission II, WG II/9
}

KEY WORDS: Underwater Photogrammetry, Digital archaeology, Cultural Heritage Documentation, UAS, Camera Calibration

\begin{abstract}
:
The 2020 underwater archaeological research in the inlet of Torre Santa Sabina - Baia dei Camerini (Municipality of Carovigno, Brindisi, Italy) represented the first phase of the pilot intervention of the Interreg Italia-Croatia UnderwaterMuse project. The project aims to enhance and make accessible the vast underwater heritage of the areas involved; this will be done by creating submerged archaeological parks and using virtual reality's narrative and communicative tools and platforms. During the 2020 campaign, different survey activities were carried out using several techniques and methodology to produce the area's multi-scale documentation. First of all, the entire stretch of coast was mapped with UASs (Uncrewed Aerial Systems) flights to reconstruct the coastal landscape in various phases. Furthermore, an underwater photogrammetric survey carried out by expert scuba divers has been achieved in the wreck's aft area (the site analyzed during the 2020 excavation activities). The fruitful synergy between the various actors involved and the support of the territory and the community has allowed the achievement of this campaign's objectives, preliminary to the broader and more articulated intervention foreseen for the following year.
\end{abstract}

\section{INTRODUCTION}

In the last years, we assisted in the significant growth of photogrammetry applications in underwater environments. This methodology allows us to document, reconstruct and restore the surveyed underwater assets virtually (Bandiera et al., 2015) and make them accessible remotely (not only to the broad public but also to specialists across the globe). Those aspects are crucial since underwater cultural sites are, for their intrinsic nature, among the most difficult-to-reach heritage. The difficulty of operating in water environments derives from the operator's reduced stay time on the site and environmental conditions that might affect the survey (such as light condition, turbidity of the water, etc.), reducing its overall quality. For improving the study of the documented cultural heritage artifacts and sites, it is decisive to adopt the correct photogrammetric principles to achieve 3D metric products consistent and coherent with the survey's real object. Geomatics provides sensors and techniques that allow scientists and professionals to efficiently record, process, and present data related to underwater archeological sites. These techniques' potentialities and problems have already been addressed in the past (Ballarin et al., 2020); however, new emerging sensors and applications denote the need to continue investigating and evaluating different approaches. The adoption of low-cost sensors is becoming more common in recent days (Capra et al., 2015), and the possibility of processing and quickly obtain photogrammetric point clouds cannot be separated from the need for high metric accuracy, which is necessary for a trustworthy survey in cultural heritage documentation (Capra et al., 2017). As such, multi-image photogrammetry has proven to be an affordable methodology, supporting underwater archaeological activities with reliable results (Balletti et al., 2016).

\footnotetext{
* Corresponding author

${ }^{1}$ www.italy-croatia.eu/web/underwatermuse
}

1.1 Baia dei Camerini in Torre Santa Sabina: the case study of the late-imperial Roman shipwreck

This paper is related to the photogrammetric survey of the lateimperial era roman shipwreck, located in Baia dei Camerini, Torre Santa Sabina (BR), Italy, and its surrounding territories. An integrated topographic and photogrammetric UAS survey has been conducted in this framework, combined with an underwater close-range photogrammetric survey. The activities of the geomatics survey presented in this paper aim to provide reliable support for the spatial contextualization and the georeferentiation of the different data acquired during the 2020 archaeological excavation campaign of the shipwreck of Torre Santa Sabina and its surroundings (Figure 1).

This investigation campaign is in continuity with the previous researches of the UniSalento project "L'Approdo Ritrovato" (from 2007 to 2012). However, it marks an important novelty: Torre Santa Sabina becomes the scenario of a pilot intervention of the international UnderwaterMuse ${ }^{1}$ project, which aims to enhance and make accessible the vast underwater heritage of the areas involved, otherwise invisible or reserved for a few, through the creation of submerged archaeological parks and the narrative and communicative use of virtual reality.

Torre Santa Sabina is also the site of a well-preserved shipwreck found on the seabed of Baia dei Camerini in the 1970s; it is related to a Roman ship dated back between the end of the 3rd and the beginning of the 4th century AD. The ship's hull, which is still on the seabed, was over 20 meters long and relatively heavy in tonnage. There is no doubt that this wreck is one of the most interesting in the Mediterranean Sea, according to its exceptional state of conservation that allows understanding the details of the construction technique (Auriemma, 2012). 


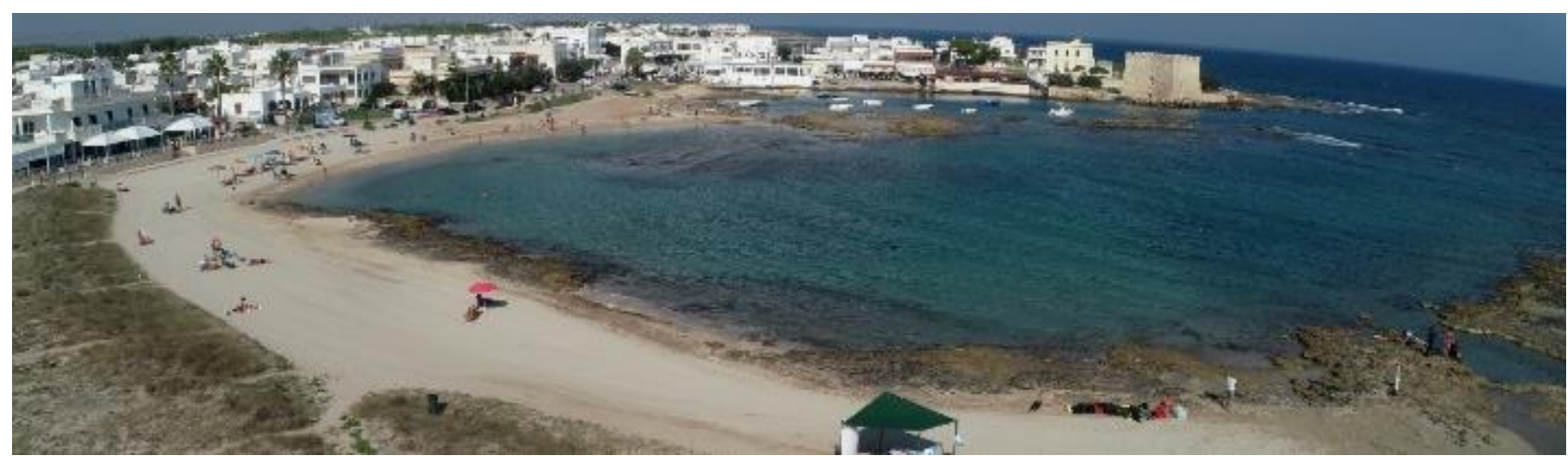

Figure 1. Panoramic view of the coastline of Baia dei Camerini, Torre Santa Sabina (Carovigno, Brindisi, IT).

\section{MATERIALS AND METHODS}

The area of the survey is represented by the shore portion related to Baia dei Camerini, Baia della mezzaluna, and the south-eastern part of the Baia dell'Isoletta, located in Santa Sabina (BR)

Two main survey activities were carried out in the wreck area and the connected surrounding to integrate aerial and underwater data (Benjamin et al., 2019). First of all, a complete multi-scale UAS survey has been carried out using the possibility offered by the on-board GNSS that allows the direct georeferencing approach: using RTK (Real-Time Kinematik) or PPK (Post-Processing Kinematic) solutions. Furthermore, a second activity concerned the underwater survey of the aft area of the roman shipwreck via close-range photogrammetry has been achieved.

\subsection{UAS data acquisition and processing}

During the 2020 campaign before the underwater acquisitions to define the coastal landscape, a complete multi-scale UAS survey has been carried out starting from Baia dei Camerini up to the Baia dell'isoletta. The aims of the acquisition were related to the archaeologists' need to obtain high-resolution maps useful for improving the possibility of founding traces or signals connected to undiscovered hidden villages. Another aspect was connected to obtaining large-scale reference support for adding all the information related to the shipwreck surveyed during previous archaeological campaigns.

According to those objectives and to testing different solutions, two platforms were selected. All the area was covered using the well-known commercial platforms Phantom 4 RTK by DJI and the eBee $X$ by Sense Fly equipped with the S.O.D.A. 3D camera. The S.O.D.A. has a resolution of $20 \mathrm{MP}$ with a sensor size of 13.2 $\mathrm{x} 8.8 \mathrm{~mm}$ and a focal length of $10.6 \mathrm{~mm}$. (Table 1).

\begin{tabular}{|l|l|l|}
\hline Resolution [pix] & Focal length [mm] & Pixel size $[\mu \mathrm{m}]$ \\
\hline $5472 \times 3648$ & $10,6 \mathrm{~mm}$ & 2,4 \\
\hline
\end{tabular}

Table 1. eBee X camera main technical specifications.

The eBee $X$ is the latest fixed-wing platform developed by SenseFly ${ }^{2}$ with a wingspan of $1.16 \mathrm{~m}$ and a weight of $1.4 \mathrm{Kg}$. The UAS is equipped with a high-quality dual-frequency GNSS that could work in RTK (Real-Time Kinematic) or PPK (Post Processing Kinematic). The platform could load several sensors in the visible and non-visible spectrum with different characteristics; the most exciting sensor for 3D mapping purpose is without any doubt the new S.O.D.A. 3D, which allows capturing 3 images ( 1 nadir and 2 obliques) along the flight path changing the camera orientation during flight (Figure 2).

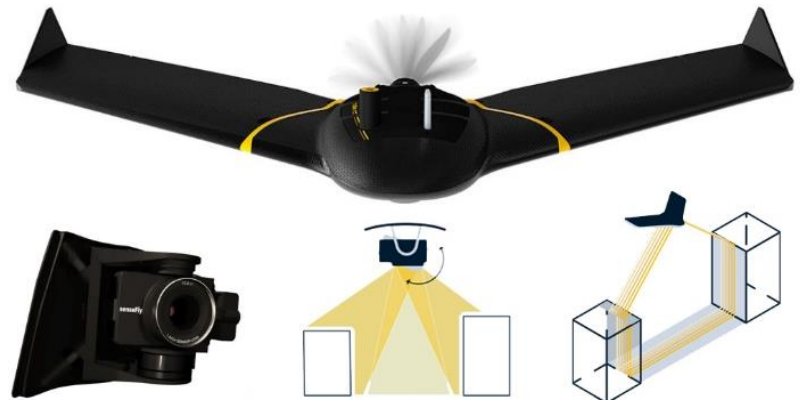

Figure 2. The eBee $X$ fixed-wing platform with the SODA 3D camera and the scheme of the camera tilting option.

In the surveyed area, 3 flights with an elevation of around $130 \mathrm{~m}$ that mean a Ground Sample Distance (GSD) of $3 \mathrm{~cm}$ were performed to cover all the area (Figure 3), from Baia dei Camerini to Baia dell'Isoletta. For the data acquisition, the eMotion software has been employed; the lateral overlapping was set up at $60 \%$ and the Longitudinal at $80 \%$. According to the previous test reported in (Sammartano et al., 2020), the first flight was performed only with nadir acquisition. On the other hand, the second and the third were carried out using the possibility of acquiring oblique images employing the camera's tilting option. The second and the third flights were designed with the same paths but in opposite directions. Using the proposed approach, the nadir view's quality (mainly the longitudinal overlapping) is maintained (according to the dedicated flight), not always guaranteed using the tilting option.

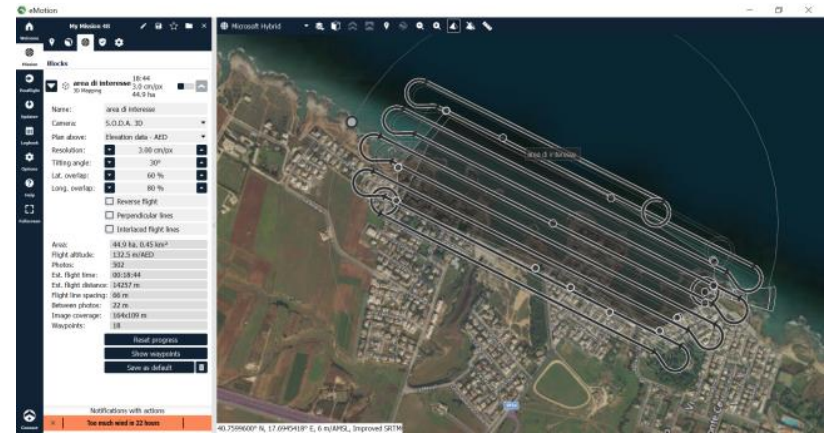

Figure 3. Screenshot of the eMotion flight plan of the surveyed area.

During the flight acquisition, the PPK option was selected. As is well known, using this option is possible to acquire and store in the drone the RAW GNSS data during the flight and post-process its using data provided by a reference station on the ground.

${ }^{2}$ www.sensefly.com 
The PPK processing was achieved using eMotion which can handle the georeferencing and prepare the images required for the next steps. The process is fully automatic, but some parameters need to be accurately checked to understand the required accuracy. The workflow combine GNSS UAS acquired data with the GNSS data of the reference station on the ground; the geographic coordinates of the ground station needs to be manually inserted in the software with some other information such as the antenna type and height from the ground vertex. The next step is the processing, where the software can re-estimate the camera poses according to the GNSS data; in the analyzed area, the precision after the post-processing was $4,5 \mathrm{~cm}(\sigma)$.

The same area was overflown with the Phantom 4 RTK multirotor platform. This UAS is equipped with a 1" CMOS camera with a mechanical shutter $(8,8 \mathrm{~mm}$ of focal length) that can acquire images in different configurations thanks to the 3 axis gimbal system (Table 2).

The images were collected at an elevation of $50 \mathrm{~m}$ (GSD of 1,36 $\mathrm{cm}$ ) with a lateral overlapping of $60 \%$ and $80 \%$ longitudinal. Six different flights (Figure 4) were carried out, and only nadir images were captured in the surveyed area.

\begin{tabular}{|l|l|l|}
\hline Resolution [pix] & Focal length [mm] & Pixel size $[\mu \mathrm{m}]$ \\
\hline $5472 \times 3648$ & $8,8 \mathrm{~mm}$ & 2,4 \\
\hline
\end{tabular}

Table 2. DJI Phantom 4 RTK camera main technical specifications.

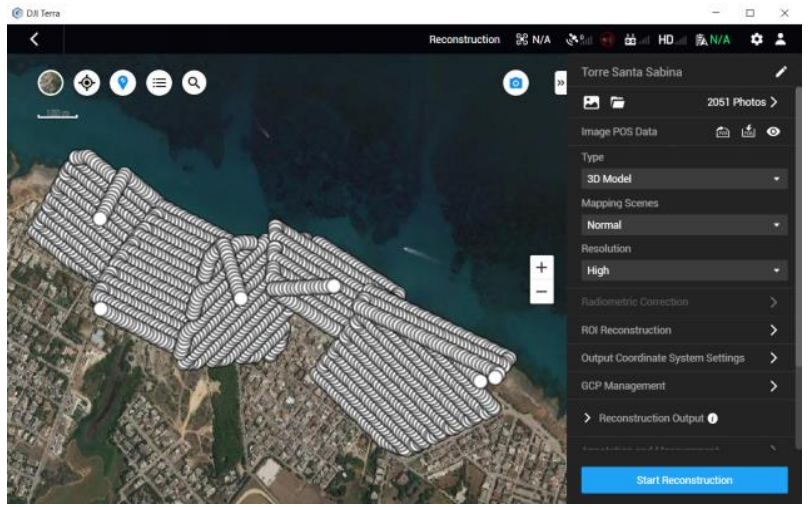

Figure 4. Screenshot of the DJI Terra software with the acquired UAS data using the Phantom 4 RTK.

The original aim was to document the land following the traditional photogrammetric pipeline and extract 3D information of the seabed using an approach like the one reported in (Agrafiotis et al., 2019). Unfortunately, due to the sea's condition, extremely rough during the flight days, it was impossible to extract any 3D data of the seabed using the UAS images despite the area being characterized by very shallow water. The flights achieved using the Phantom 4 RTK was carried out adopting the solution known as NRTK (Network Real-Time Kinematic) using an active connection of the platform to a GNSS permanent network: HxGM smartnet service from Hexagon ${ }^{3}$. Following this approach, the GNSS correction is transmitted via GSM to the platform and applied in real-time to the acquired images. The geotag precision using this approach is usually in the range of 3 $4 \mathrm{~cm}$, comparable with the one achievable with a PPK solution. As usual, before the flights, since the main objective from the Geomatics point of view is to evaluate the geometric accuracy of the generated outputs, some points (42) were placed and measured on the field to have a set of points usable as GCPs (Ground Control Points) and/or CPs (Check Points) (Figure 5). The points' survey was carried out using an NRTK approach that allows obtaining the $3 \mathrm{D}$ coordinates of the measured markers with an average accuracy of about $2 \mathrm{~cm}$. In the area of Torre Santa Sabina, both natural (e.g., natural and artificial features clearly visible from the acquired images) and artificial markers ( $0.4 \times 0.4 \mathrm{~m}$ panels) were employed. This part of the survey was carried out using a Leica GNSS receiver (GS14 model). Moreover, a GNSS network with4 vertexes were measured using static observation ( 1 hour for each baseline, sample rate $5 \mathrm{sec}$ ). The network was defined and adjusted using the software LGO (Leica Geo Office) thanks to 3 permanent GNSS stations (Brindisi, Conversano e Taranto) of the Hexagon network, allowing to obtain the correct coordinates of the measured points. The raw data, measured by total station, have been processed starting from the vertexes coordinates using MicroSurvey StarNet 7. All the coordinates are expressed in UTM WGS $84-$ $33 \mathrm{~N}$ and geoidic elevation, calculated using the IGM grids via ConveRgo. The photogrammetric data were processed using SfM software (DJI Terra and Pix4D) to obtain the traditional output (3D models and orthoimages) useful for the Underwater Muse project's different researchers (Figure 6). Three different approaches were followed; in a first approach (A), all the measured points were considered as CPs; in a second approach (B), all the measured points were used as GCPs; in a third approach (C), all the points were marked as CPs, except for 5 points used as GCPs (highlighted in yellow in figure 5). As it is possible to observe from the following Table 3 , the results validate the capability of performing a survey-grade accuracy for both platforms. Using a well-distributed set of GCPs (as in approach C) allows lowering the RMSE of GCPs and CPs further; camera calibration has been performed following a selfcalibration approach during the image alignment phase.

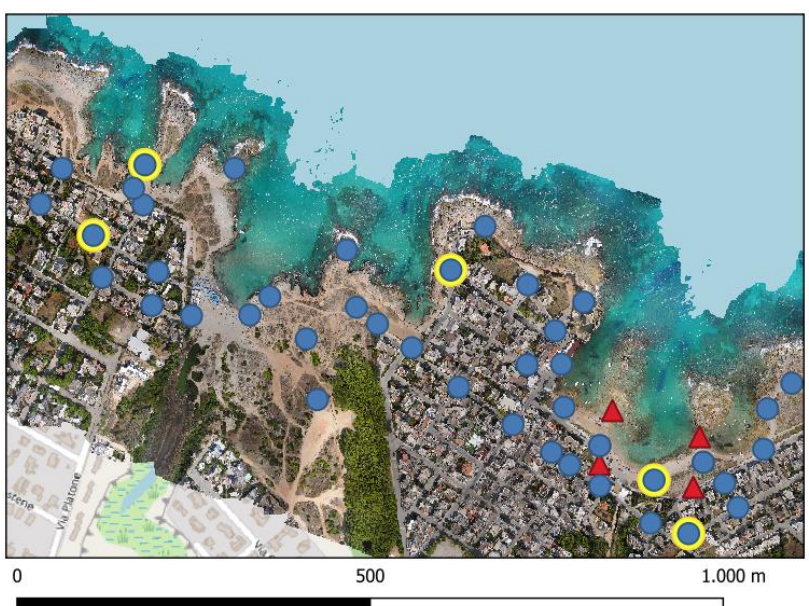

Figure 5. UAS orthoimage of the shore of Santa Sabina, with superimposed the topographic vertexes (red triangles) and the

GCPs (blue dots) used for the georeferentiation of the photogrammetric flights.

\begin{tabular}{|c|c|c|c|c|c|c|c|}
\hline \multirow{3}{*}{ Approach } & \multirow{3}{*}{ Software } & \multicolumn{6}{|c|}{ RMS Error [cm] } \\
\cline { 3 - 8 } & & \multicolumn{3}{|c|}{ GCPs } & \multicolumn{4}{c|}{ CPs } \\
\cline { 3 - 8 } & & $\mathrm{X}$ & $\mathrm{Y}$ & $\mathrm{Z}$ & $\mathrm{X}$ & $\mathrm{Y}$ & $\mathrm{Z}$ \\
\hline (A) all & PIX4D & n/a & n/a & n/a & 2,3 & 2,9 & 2,7 \\
\cline { 2 - 8 } CPs & DJI Terra & n/a & n/a & n/a & 2,1 & 2,6 & 3,1 \\
\hline (B) all & PIX4D & 1,5 & 1,7 & 1,5 & n/a & n/a & n/a \\
\cline { 2 - 8 } GCPs & DJI Terra & 1,1 & 1,2 & 0,9 & n/a & n/a & n/a \\
\hline (C) five & PIX4D & 1,5 & 0,7 & 0,8 & 2,0 & 2,7 & 2,4 \\
\cline { 2 - 8 } GCPs & DJI Terra & 1,2 & 0,6 & 0,6 & 1,6 & 2,7 & 3,3 \\
\hline
\end{tabular}

Table 3. RMS error for GCPs and CPSs referred to the three different approaches followed using the two software.

${ }^{3}$ https://hxgnsmartnet.com/ 


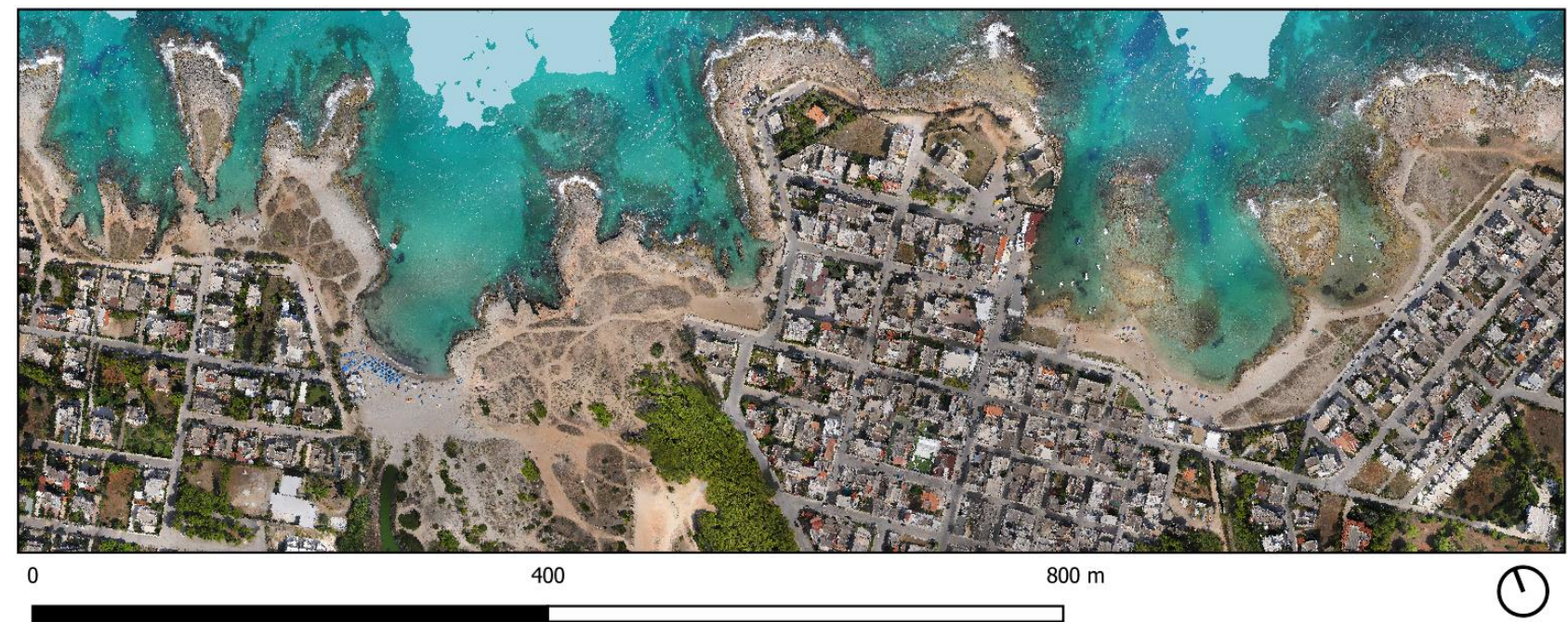

Figure 6. UAS orthoimage of the shore of Santa Sabina (eBee X).

\subsection{Underwater data acquisition and processing}

Photogrammetric underwater data collection has been performed in two days in September 2020 and focused on the aft part of the roman shipwreck survey.

The underwater photogrammetric acquisition (Figure 7) has been performed using an Olympus Tough TG-6 digital camera (Table 4) following different acquisition schemas (nadir and oblique) useful for obtaining a complete $3 \mathrm{D}$ and $2 \mathrm{D}$ documentation. The employed camera can operate without underwater housing at a maximum depth of $15 \mathrm{~m}$; thus, no additional housing has been used during the acquisition phase. This also allowed to reduce image residuals systematic patterns that are usually detected when dome ports are used (Menna et al., 2020). The camera also integrates an underwater mode that performs an on-the-fly radiometric adjustment. Given also the shallow depth on which the survey took place, this option was used without further color correction adjustments in pre-processing.

According to the position of the wreck (depth of about $3 \mathrm{~m}$ ) before the image acquisition, some markers were placed on the seabed and measured using via a topographic approach using a 4 $\mathrm{m}$ long pole and a prism, measured via TS (total station) side shot acquisitions from the shore (Figure 8). Two scuba divers handled the prism to make it vertical before the TS measurements.

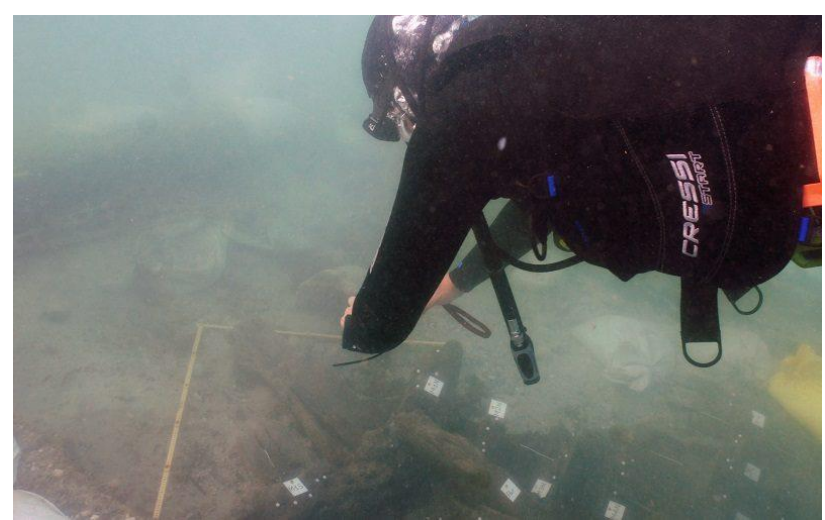

Figure 7. Image acquisition phase during the underwater photogrammetric survey of the Roman shipwreck in Torre Santa Sabina.

\begin{tabular}{|l|l|l|}
\hline Resolution [pix] & Focal length [mm] & Pixel size $[\mu \mathrm{m}]$ \\
\hline $4000 \times 3000$ & $4,5 \mathrm{~mm}$ & 1,56 \\
\hline
\end{tabular}

Table 4. Olympus TG-6 camera main technical specifications.

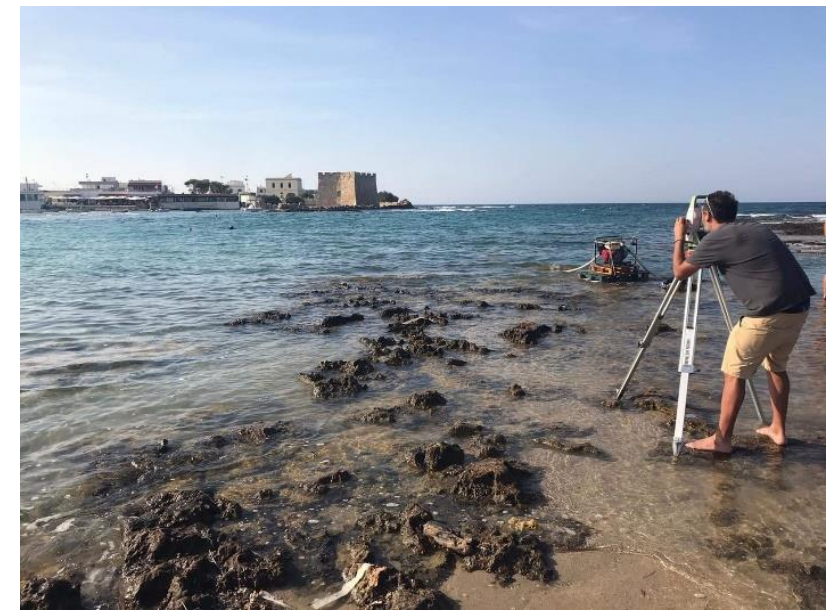

Figure 8. The image shows the topographical survey operation in Torre Santa Sabina performed to measure the position of the underwater markers.

The measurement of the points' coordinates via this method was affected by errors due to the uneven verticality of the pole caused by the wind and the sea waves. This has been taken into account during the evaluation of the survey accuracy, as a higher RMSE on the measured GCPs is expected.

To evaluate the reliability of an easy and fast survey technique, part of this work focused on assessing the quality of a photogrammetric 3D model generated via a free-net adjustment approach (followed by assigning a scale based on known distances). The 3D model developed following this method has been compared with those generated employing the previously surveyed set of GCPs.

The underwater photogrammetric datasets were processed using the software Agisoft Metashape 1.6.5. The first dataset was composed of images acquired during the first day of the photogrammetric survey. Following the software's operative workflow, at first, images have been oriented. A set of 5 previously measured GCPs has been used to provide correct georeferentiation to the survey; at the end, dense point clouds, DEM, and orthoimages have been generated (Figure 9). 


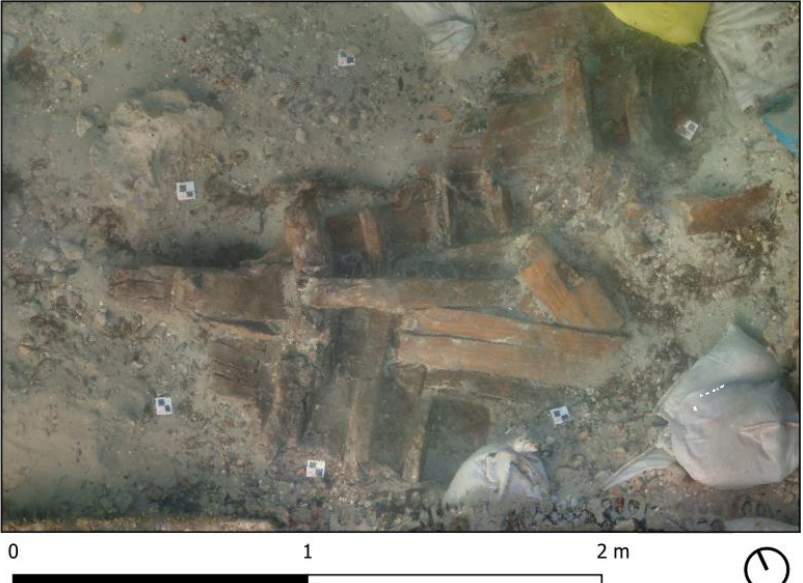

Figure 9. Orthoimage of the aft part of the shipwreck, georeferenced using five $10 \mathrm{~cm}$ squared checkerboard markers, measured with celerimetric method.

In this case, since no pre-calibration procedure was followed, camera calibration has been performed following a selfcalibration approach during the image alignment phase. The characteristics related to this first dataset are reported in Table 5, while the GCPs RMS errors are reported in Table 6.

\begin{tabular}{|l|l|l|l|}
\hline Total images & 343 & Oriented images & 336 \\
\hline $\begin{array}{l}\text { Average acquisition } \\
\text { distance }[\mathrm{m}]\end{array}$ & 0,83 & Tie points & 335.584 \\
\hline GSD $[\mathrm{mm} / \mathrm{pix}]$ & 0,2 & Projections & 937.136 \\
\hline Surveyed area $\left[\mathrm{m}^{2}\right]$ & 4,5 & $\begin{array}{l}\text { Reprojection } \\
\text { error [pix] }\end{array}$ & 1,42 \\
\hline
\end{tabular}

Table 5. Characteristics of the photogrammetric dataset collected on the first day of the survey.

\begin{tabular}{|c|c|c|c|c|c|}
\hline & \multicolumn{5}{|c|}{ RMS error [cm] } \\
\hline $\begin{array}{c}\text { Number of } \\
\text { GCPs }\end{array}$ & $\mathrm{X}$ & $\mathrm{Y}$ & $\mathrm{Z}$ & $\mathrm{XY}$ & $\mathrm{XYZ}$ \\
\hline 5 & 1,8 & 1,6 & 2,4 & 2,4 & 3,5 \\
\hline
\end{tabular}

Table 6. RMS error for GCPs referred to the photogrammetric survey of the aft part of the wreck.

The second dataset was composed of images acquired during the second day of the photogrammetric survey. Here before the survey, a necessary archaeological procedure was applied for the characterization of the shipwreck via an operation that allowed to mark clearly the most significant elements of the wreck using small portions of colored electrical cables, some thumbtacks "push-pin" and plastic cards. Push-pin were also used to indicate where wooden nails were previously located (Figure 10). The same operative workflow of the first dataset has been used. However, this time the 3D model has been generated via a freenet adjustment, assigning a scale to the model via a least-squares adjustment on two scale bars placed in the surveyed scene. In this case, the camera calibration certificate of the previous dataset has been used to provide an initial estimation of the camera's internal parameters. The characteristics related to this second dataset are reported in table 7 . scanners/software/leica-cyclone/leica-cyclone-3dr

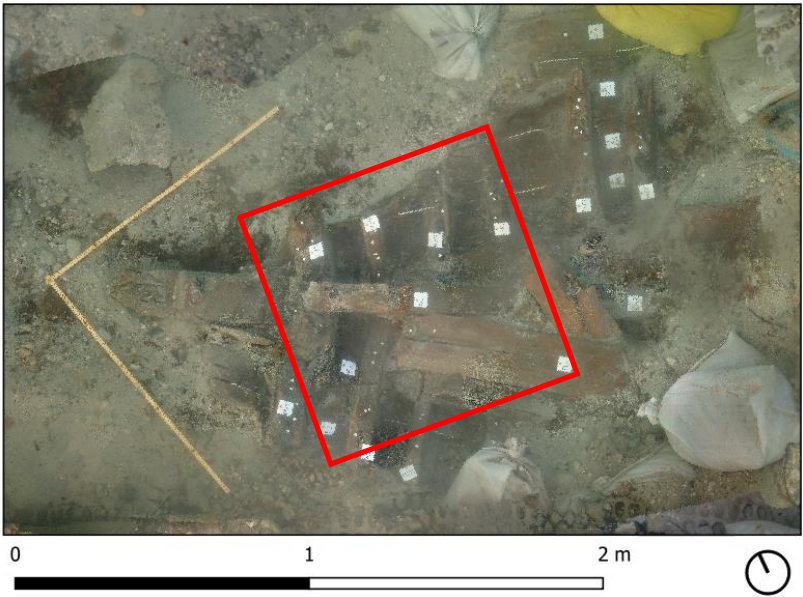

Figure 10. Orthoimage of the aft part of the shipwreck, generated via free-net adjustment after the archaeological categorization. In red, the portion of the analysis of Figure 11.

\begin{tabular}{|l|l|l|l|}
\hline Total images & 284 & Oriented images & 279 \\
\hline $\begin{array}{l}\text { Average acquisition } \\
\text { distance }[\mathrm{m}]\end{array}$ & 0,78 & Tie points & 218,594 \\
\hline GSD $[\mathrm{mm} /$ pix] & 0,2 & Projections & 634,527 \\
\hline Surveyed area $\left[\mathrm{m}^{2}\right]$ & 4,5 & $\begin{array}{l}\text { Reprojection } \\
\text { error [pix] }\end{array}$ & 1,7 \\
\hline
\end{tabular}

Table 7. Characteristics of the photogrammetric dataset collected on the second day of the survey.

To evaluate the quality of the two 3D models, the same portion $\left(1 \mathrm{~m}^{2}\right)$ of the two models has been compared, performing a rigid roto-translation (without changing the scale of the models). For point clouds management and analysis, the commercial software Leica Cyclone 3DR ${ }^{4}$ has been used; the two clouds have been aligned using the best fit option of the above-mentioned software, allowing for a registration using the ICP (Iterative Closest Point) algorithm. This resulted in an average error of $2,8 \mathrm{~mm}$ and a standard deviation of 3,5 $\mathrm{mm}$. It has been therefore performed a C2C (Cloud to Cloud) comparison (Figure 11).

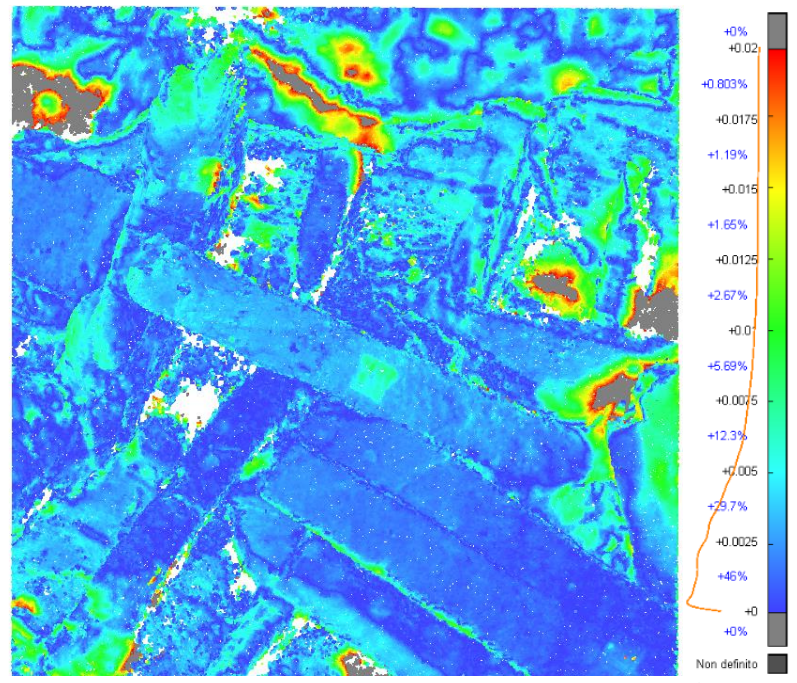

Figure 11. Comparison between the same portion $\left(1 \mathrm{~m}^{2}\right)$ of the two dense point clouds generated in the two days of the underwater photogrammetric survey using the two different georeferentiation techniques. 
The max value of detectable deviation has been imposed at $2 \mathrm{~cm}$. Even if these methods provide an accurate value of the local deviation between the two models, it is essential to clarify that this value is often overestimated since the algorithm calculates the distance value among a couple of points of the two point clouds that are relatively closest to each other (nearest neighbor distance). This value is always higher than the minimum distance obtained if both models were infinitely dense.

It is possible to observe that the deviation between the two models is less than $1 \mathrm{~cm}$ for $94 \%$ of the points. Moreover, the parts of the models with higher discrepancy are mainly related to the seabed and to sands accumulation that likely was moved between the two excavation phases of the two days. The use of this technique has some limits because the survey is performed in a relative reference system. This means that it is impossible to put the derived products in relation to each other or prior/subsequent survey. Moreover, in the case of higher surface extension of the survey, it will be required to place additional and more extended scale bars, as error propagation will likely increase whenever more extended photogrammetric blocks are scaled using relatively small reference scale bars. However, this technique remains crucial in surveys performed at higher depts, where longer poles are not usable, and the georeferentiation has to be performed employing other methods and instruments, such as SBL (Short baseline) acoustic positioning systems.

Along with the underwater photogrammetry operations, a multibeam survey for the underwater seabed definition has been carried out with the R2 Sonic 2020 equipped by the R2INS IMU platform integrated with an RTK GNSS antenna necessary for georeferencing the acquisition (Figure 12). In this paper, the bathymetric survey here reported was not analyzed in relation to the DSM obtained by photogrammetry data since the level of detail of the two underwater surveys was not comparable. Regarding this part, further analysis will be assessed in future studies.

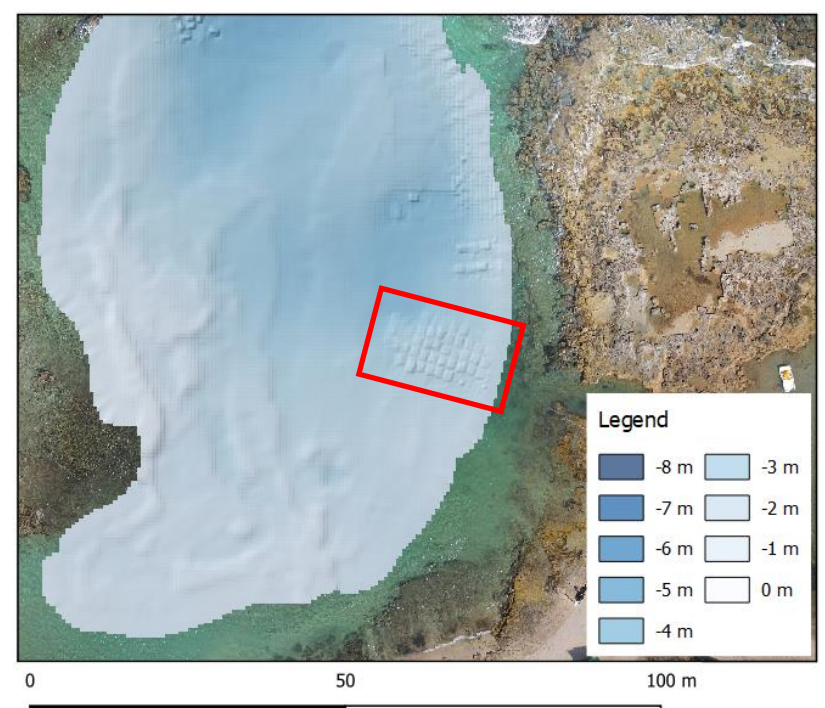

Figure 12. DEM of the seabed of Baia dei Camerini obtained after the multi-beam survey; in red, the concrete blocks that protect the roman shipwreck's archaeological site area.

\section{COMPARISON WITH THE 2007 SURVEY}

Given the importance of legacy data, it was interesting to compare data obtained and processing techniques followed in the
2020 acquisition campaign with a previous survey campaign performed in 2007 (Alfonso, 2007). Images of the 2007 excavation campaign dataset were captured using a Nikon D50 (3008 x 2000 pixels) with underwater housing. The dataset composition is showed in the following Table 8 .

\begin{tabular}{|l|l|l|}
\hline Number of images & Focal length [mm] & Acquisition \\
\hline 74 & 18 & Nadiral \\
\hline 79 & 24 & Nadiral \\
\hline 321 & 35 & Oblique \\
\hline
\end{tabular}

Table 8. Characteristics of the photogrammetric dataset related to the 2007 survey.

Since the acquired images suffered a severe chromatic aberration (Agrafiotis et al., 2017), a radiometric pre-processing has been performed (Figure 13) using the adaptation of the $\mathrm{C}$ code of the ACE (Automatic Color Enhancement) image color enhancement filter (Getreurer, 2012), integrated into the Image Enhancement process tool of the i-MARECULTURE project ${ }^{5}$.

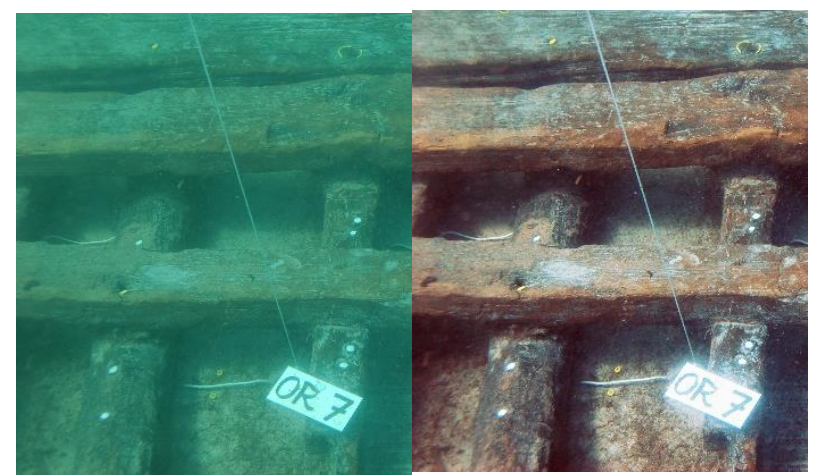

Figure 13. On the left, an image of the 2007 dataset before the radiometric correction; on the right, the same image after applying the ACE filter.

Because absolute georeferentiation data was not available, the operative workflow previously described (generation of a 3D model via a free-net adjustment) has been followed, assigning a scale to the model via a least-squares adjustment on six measures obtained exploiting the metric rulers attached to the archaeological quadrillage (Barker, 1993), placed in the scene for performing the direct survey. To compare and relate the 2007 and the 2020 survey (Table 9), it was necessary to manually connect the two orthoimages on the same reference system, exploiting a small overlapping part. This made it possible to produce a comprehensive orthomosaic and a DEM (Figure 14) to facilitate the shipwreck shape and extension's comprehension and plan future surveys and eventual recovery operations.

\begin{tabular}{|c|c|c|c|}
\hline & \multirow{2}{*}{$\begin{array}{l}\text { Direct } \\
\text { survey }\end{array}$} & \multicolumn{2}{|c|}{ Photogrammetry survey } \\
\hline & & Photomodeler & Metashape \\
\hline Acquisition time $[\mathrm{h}]$ & 9:00 & $0: 30$ & $0: 30$ \\
\hline Operators & 2 & 1 & 1 \\
\hline Processing time $[\mathrm{h}]$ & $11: 00^{1}$ & $20: 00^{2}$ & $1: 00^{2}$ \\
\hline Repr. Error [cm] & \pm 8 & \pm 1 & $\pm 0,05$ \\
\hline Georef. Error $[\mathrm{cm}]$ & $\mathrm{n} / \mathrm{a}$ & $\mathrm{n} / \mathrm{a}$ & 3,5 \\
\hline \multicolumn{4}{|c|}{${ }^{1}$ Only referred to the production of drawings } \\
\hline
\end{tabular}

Table 9. Comparison between direct and photogrammetry survey with both Photomodeler (old) and Metashape (new) approach. Data are referred to a portion of the study of $4,5 \mathrm{~m}^{2}$.

5 https://imareculture.eu/downloads/project-tools/image-enhancementprocess-tool/ 


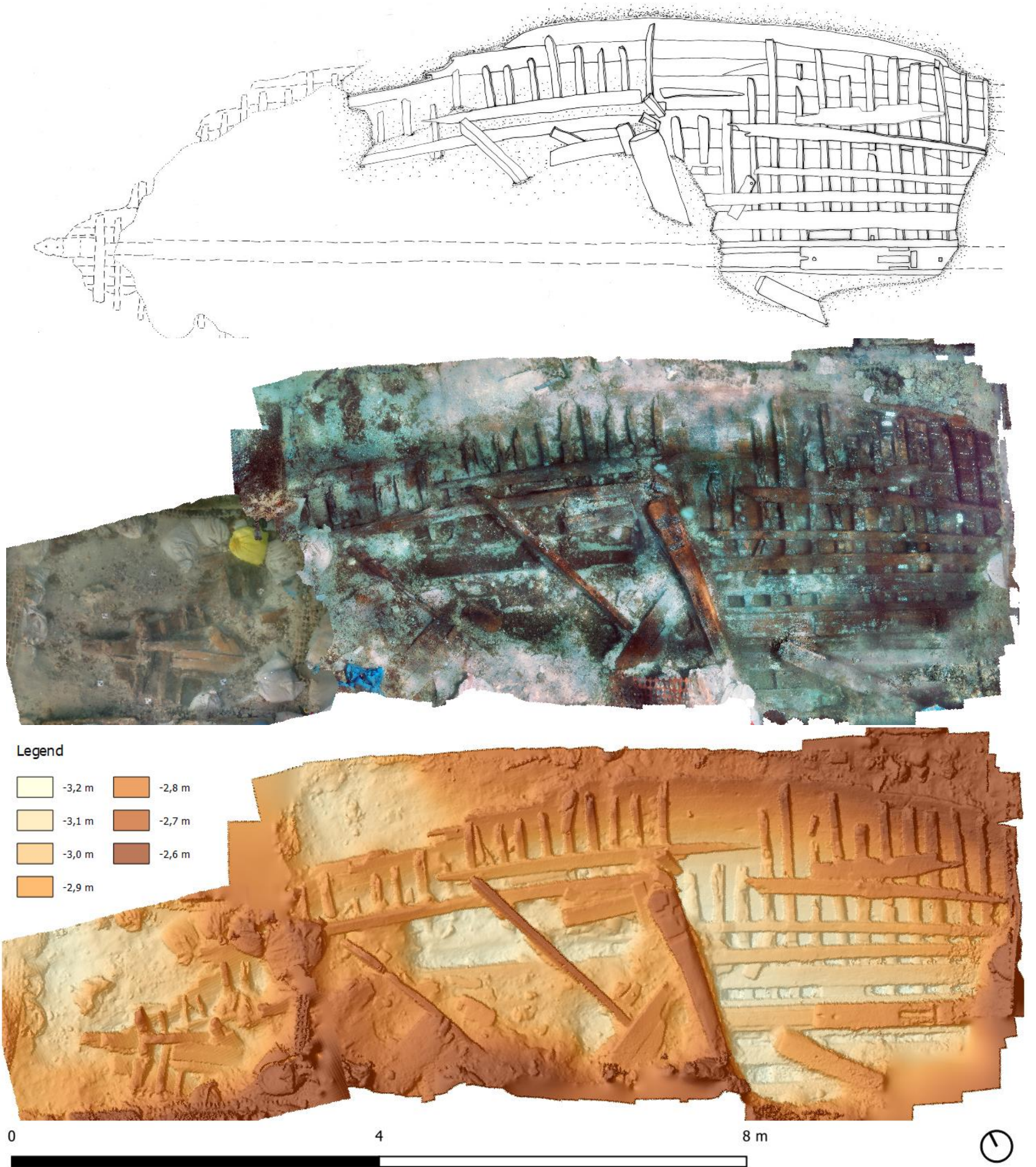

Figure 14. On the top, drawing of the shipwreck produced via direct survey in 2007; on the center, RGB orthoimages of the two parts of the wreck surveyed in 2007 (right) and 2020 (left); on the bottom, DEMs of the same orthoimages of the two surveys.

\section{DISCUSSION AND CONCLUSIONS}

The main result of the work presented in this paper is related to a comprehensive survey of the archaeological site and its surroundings, allowing archaeologists and other researchers to carry out their activities in the framework of verified and updated metric supports.

Concerning the photogrammetric survey performed using UAS, it was possible to document the sites and their immediate surroundings thanks to the generation of metric products (orthophotos, digital surface models, and 3D models) obtained via photogrammetric techniques based on SfM (Structure From Motion) algorithms.

During the UAS data processing, a quality evaluation of the direct photogrammetric approach using the two platforms was carried out and accurately assessed. The proposed georeferentiation method showed that it is possible to obtain good results with a standalone PPK approach, even without any measured GCPs.

An essential part of the activities carried out in the underwater environment focused on the photogrammetric acquisition of the aft part of the roman shipwreck, allowing both an understanding 
of the survey techniques to use in a future survey campaign, both the possibility of putting in relation the new data with the ones form a survey performed 14 years before this study. The presented results show that modern photogrammetric algorithms can provide a valuable alternative to direct surveys in the documentation of archaeological sites' excavation phases.

The use of digital photogrammetry techniques applied to the archaeological survey of underwater sites can consistently speed up the survey operations without neglecting the gathered data's quality and reliability. Implementing these procedures also provides better conditions for the operators involved due to the reduction of the overall diving time. Critical aspects of applying this methodology are mainly related to the preliminary assessment of the camera calibration.

Carrying out the survey in very shallow waters provides advantages from the logistic perspective and some drawbacks in the GCPs measurement via traditional topographic methods. These aspects will be assessed and furtherly refined given the future 2021 survey campaign, in which there will be the possibility to extend the survey to a broader area of the shipwreck for comprehensive documentation of the archaeological site.

\section{ACKNOWLEDGEMENTS}

The authors would like to thank Mario Mazzoli, Marco Vitelli and Bernardino Rocchi of the A.S.S.O. (Archeologia Subacquea Speleologia Organizzazione) onlus, for the important and experienced technical support provided in the phase of the underwater survey. Many thanks to Paolo Maschio for the UAS and topographic acquisition support and Luigi Coluccia, Angelo Colucci, Carmela Jaia, Melissa Mele, Andrea Mazzarulli, Andrea Podestà, and Fernando Zongolo for the help in the underwater archaeological surveys, and to Valeria De Ruvo and Erica Forti for the help in the geomatics data collection and processing. Thanks to Cristiano Alfonso for providing the 2007 imagery dataset. Thanks to Antonella Antonazzo for taking care of the organizative aspects of the mission, and to to Giuliano Volpe (Dipartimento di Studi Umanistici of the Università degli Studi di Bari Aldo Moro), Danilo Leone and Mariuccia Turchiano (Dipartimento di Studi Umanistici of the Università degli Studi di Foggia) for assisting the scientific direction of the archaeological mission. The authors would like to acknowledge the Municipality of Carovigno for the logistical support and the kind availability of the Consorzio Albergatori Carovigno, which hosted the researchers during the whole excavation period. Thanks to the Ministero dei Beni e delle Attività Culturali e del Turismo and the Soprintendenza archeologia belle arti e paesaggio Brindisi, Lecce e Taranto for the excavation permit allowance. The authors would like to thank the project partners of the UnderwaterMuse (Immersive Underwater Museum Experience for a wider inclusion) Interreg Italy-Croatia project for the economic support that made this research possible. This scientific paper is a product of the UnderwaterMuse project, funded by the Interreg V-A Italy-Croatia 2014-2020 chapter.

\section{REFERENCES}

Agrafiotis, P., Drakonakis, G. I., Georgopoulos, A., \& Skarlatos, D. (2017). The effect of underwater imagery radiometry on 3D reconstruction and orthoimagery. International Society for Photogrammetry and Remote Sensing, XLII-2/W3, 25-31.

Agrafiotis, P., Karantzalos, K., Georgopoulos, A., \& Skarlatos, D. (2019). Shallow Water Bathymetry Mapping from UAV Imagery based on Machine Learning. ISPRS Journal of Photogrammetry and Remote Sensing, XLII-2/W10, 9-16.
Alfonso, C. (2007). Torre S. Sabina. Il rilievo del relitto: tecniche tradizionali e fotogrammetria non convenzionale. Atti del III Convegno Nazionale di Archeologia Subacquea (Manfredona, 46 ottobre 2007), Bari.

Auriemma, R. (2012). Nuovi dati dalla costa adriatica e ionica del Salento. Histria antiqua, 21(21), 539-556.

Ballarin, M., Costa, E., Piemonte, A., Piras, M., \& Losè, L. T. (2020). Underwater Photogrammetry: Potentialities and Problems Results of the Benchmark Session of the 2019 Sifet Congress. The International Archives of Photogrammetry, Remote Sensing and Spatial Information Sciences, XLIII-B22020, 925-931.

Balletti, C., Beltrame, C., Costa, E., Guerra, F., \& Vernier, P. (2016). 3D reconstruction of marble shipwreck cargoes based on underwater multi-image photogrammetry. Digital Applications in Archaeology and Cultural Heritage, 3(1), 1-8.

Bandiera, A., Alfonso, C., \& Auriemma, R. (2015). Active And Passive 3d Imaging Technologies Applied To Waterlogged Wooden Artifacts From Shipwrecks. International Archives of the Photogrammetry, Remote Sensing \& Spatial Information Sciences, XL-5/W5, 15-23

Barker, P. (1993). Techniques of archaeological excavation. Taylor \& Francis.

Benjamin, J., McCarthy, J., Wiseman, C., Bevin, S., Kowlessar, J., Astrup, P. M., ... \& Hacker, J. (2019). Integrating aerial and underwater data for archaeology: Digital maritime landscapes in 3D. 3D Recording and Interpretation for Maritime Archaeology, 211.

Capra, A., Dubbini, M., Bertacchini, E., Castagnetti, C., \& Mancini, F. (2015). 3D reconstruction of an underwater archaelogical site: Comparison between low cost cameras. In Underwater 3D Recording and Modeling (Vol. 40, No. 5W5, pp. 67-72). International Society for Photogrammetry and Remote Sensing.

Capra, A., Castagnetti, C., Dubbini, M., Gruen, A., Guo, T., Mancini, F. T., ... \& Troyer, M. (2017). High Accuracy Underwater Photogrammetric Surveying. In 3rd IMEKO International Conference on Metrology for Archeology and Cultural Heritage.

Getreuer, P. (2012). Automatic color enhancement (ACE) and its fast implementation. Image Processing On Line, 2, 266-277.

Menna, F., Nocerino, E., Ural, S., \& Gruen, A. (2020). Mitigating image residuals systematic patterns in underwater photogrammetry. The International Archives of Photogrammetry, Remote Sensing and Spatial Information Sciences, 43, XLIII-B2-2020, 977-984

Sammartano, G., Chiabrando, F., \& Spanò, A. (2020). Oblique images and direct photogrammetry with a fixed wing platform: first test and results in Hierapolis of Phrygia (TK). The International Archives of Photogrammetry, Remote Sensing and Spatial Information Sciences, 43, 75-82. 